University of Arkansas, Fayetteville

ScholarWorks@UARK

Education Reform Faculty and Graduate

Students Publications

Education Reform

$9-1-2016$

\title{
Personality as a Predictor of Unit Nonresponse in Panel Data: An Analysis of an Internet-Based Survey
}

\author{
Albert Cheng \\ Harvard University, albert_cheng@hks.harvard.edu \\ Gema Zamarro \\ University of Arkansas, Fayetteville \\ Bart Orriens \\ Center for Economic and Social Research
}

Follow this and additional works at: https://scholarworks.uark.edu/edrepub

Part of the Educational Assessment, Evaluation, and Research Commons, Educational Leadership Commons, and the Other Educational Administration and Supervision Commons

\section{Citation}

Cheng, A., Zamarro, G., \& Orriens, B. (2016). Personality as a Predictor of Unit Nonresponse in Panel Data: An Analysis of an Internet-Based Survey. Education Reform Faculty and Graduate Students Publications. Retrieved from https://scholarworks.uark.edu/edrepub/28

This Article is brought to you for free and open access by the Education Reform at ScholarWorks@UARK. It has been accepted for inclusion in Education Reform Faculty and Graduate Students Publications by an authorized administrator of ScholarWorks@UARK. For more information, please contact scholar@uark.edu. 


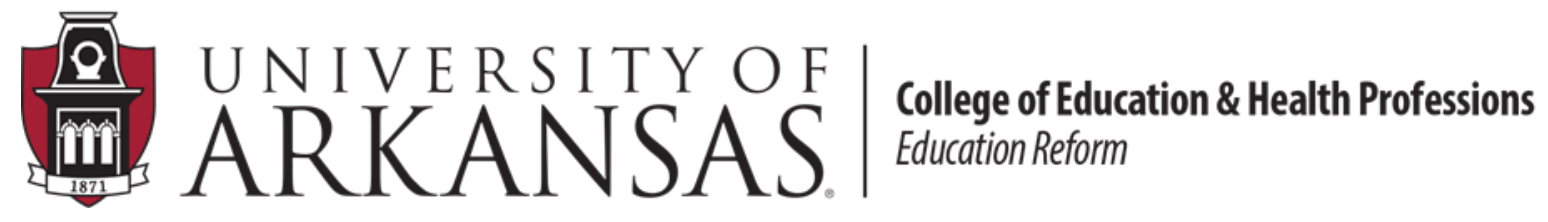

\title{
WORKING PAPER SERIES
}

\section{Personality as a Predictor of Unit Nonresponse in Panel Data: An analysis of an Internet-Based Survey}

\author{
Albert Cheng* \\ Harvard University \& University of Arkansas \\ Gema Zamarro \\ University of Arkansas \& University of Southern California \\ Bart Orriens \\ University of Southern California
}

September 2016

EDRE Working Paper 2016-12

The University of Arkansas, Department of Education Reform (EDRE) working paper series is intended to widely disseminate and make easily accessible the results of EDRE faculty and students' latest findings. The Working Papers in this series have not undergone peer review or been edited by the University of Arkansas. The working papers are widely available, to encourage discussion and input from the research community before publication in a formal, peer reviewed journal. Unless otherwise indicated, working papers can be cited without permission of the author so long as the source is clearly referred to as an EDRE working paper. 


\title{
char.asse $\cdot$ in \\ THE CHARACTER ASSESSMENT INITIATIVE
}

\section{Personality as a Predictor of Unit Nonresponse in Panel Data: An analysis of an Internet-Based Survey}

\author{
Albert Cheng* \\ Harvard University \& University of Arkansas \\ Gema Zamarro \\ University of Arkansas \& University of Southern California \\ Bart Orriens \\ University of Southern California
}

September 2016

*Corresponding author: Albert Cheng, Harvard University, Email:

albert_cheng@hks.harvard.edu. We thank Arie Kapteyn for very useful feedback on early versions of this paper. 


\begin{abstract}
Unit nonresponse or attrition in panel data sets is often a source of nonrandom measurement error. Why certain individuals attrite from longitudinal studies and how to minimize this phenomenon have been examined by researchers. However, this research has typically focused on data sets collected via telephone, postal mail, or face-to-face interviews. Moreover, this research usually focuses on using demographic characteristics such as educational attainment or income to explain variation in the incidence of unit nonresponse. We make two contributions to the existing literature. First, we examine the incidence of unit nonresponse in an internet panel, a relatively new, and hence understudied, approach to gathering longitudinal data. Second, we hypothesize that personality traits, which typically remain unobserved and unmeasured in many data sets, affect the likelihood of unit nonresponse. Using data from an internet panel that includes self-reported measures of personality in its baseline survey, we find that conscientiousness and openness to experience predict the incidence of unit nonresponse in subsequent survey waves, even after controlling for cognitive ability and demographic characteristics that are usually available and used by researchers to correct for panel attrition. We also test the potential to use paradata as proxies for personality traits. Although we show that these proxies predict panel attrition in the same way as self-reported measures of personality traits, it is unclear to what extent they capture particular personality traits versus other individual circumstances related to future survey completion. Our results suggest that obtaining explicit measures of personality traits or finding better proxies for them are crucial to more fully address the potential bias that may arise as a result of panel attrition.
\end{abstract}

Keywords: attrition, internet panel data, personality traits, paradata JEL codes: C80, C83 


\section{Introduction}

Governments and other agencies have invested many resources to administer surveys and to create longitudinal panel datasets such as the Health and Retirement Study, the English Longitudinal Study of Ageing, the Survey of Health, Ageing and Retirement in Europe, the National Longitudinal Study of Youth, the Michigan Panel Study of Income Dynamics, and the German Socio-Economic Panel. These data have been valuable for studying a variety of topics ranging from health, the labor market, retirement, and education. The availability of panel data has benefited researchers by enabling them to examine change over time or to use various analytic techniques to establish causal relationships.

Developments in technology have also facilitated collection of internet panel datasets, where nationally representative samples of respondents are regularly interviewed over the internet on a diverse set of topics. Examples of such internet panels are the CentERpanel in the Netherlands, the RAND American Life Panel, the USC Understanding America Study, GFK Knowledge Panel, and Amerispeak at the University of Chicago. These internet panels allow researchers to obtain responses to major events (e.g. elections or pandemics) with quick turnaround time. Advantages of new technologies to collect data also enable researchers to design innovative surveys that, for instance, embed experiments and randomization in the questionnaires.

Despite the advantages that both traditional panel data and internet panels provide to researchers, unit nonresponse could be an important source of bias if those responding and those not responding differ in important characteristics. This problem is especially salient in panel data, as respondents not only may refrain from answering individual questions, leading to item nonresponse, but also may decide not to participate in subsequent waves leading to unit nonresponse or panel attrition. This is a well-known issue in traditional panel datasets, where respondents are interviewed either in person or over the phone, that could lead to significant biases (see, e.g. special Spring 1998 issue of the Journal of Human Resources dedicated to longitudinal surveys). Less is known, however, about how panel attrition affects internet panels.

At the point of data collection, various suggestions, such as the provision of incentives, the utilization of different survey designs, and the implementation of various follow-up methods, have been proposed to mitigate panel attrition (Calinescue \& Schouten, 2016; Catigloino, Pforr, \& Krieger, 2008; Korbmacher \& Schroeder, 2013; Lynn, 2013; Singer et al., 1999). Researchers have also examined the magnitude of bias due to unit nonresponse in traditional panel datasets and proposed statistical techniques, often based on weighting schemes, to correct for any resulting bias after data collection has concluded (Puma, et al., 2009; Sakshaug \& Huber, 2016; Schifeling et al., 2015; Twisk, \& de Vente, 2002). These corrections, however, often rely on the assumption that researchers have information on the set of characteristics that make respondents and nonrespondents systematically different. In this respect, researchers have attempted to link panel attrition in traditional panels with demographic characteristics such as educational attainment, health, and socioeconomic status (Behr, Bellgardt, \& Rendtel, 2005; Goyder, Warriner, \& Miller, 2002; Mirowsky, \& Reynolds, 2000; Sakshaug \& Huber, 2016). However, concerns remain that these often available demographic characteristics might not control for all differences among respondents and nonrespondents in which case simple reweighting approaches would not be able to fully correct for panel attrition bias. For instance, recent research has highlighted how even difficult-to-find respondents also present different survey outcomes than respondents that are more easily recruited. This suggests that nonrespondents, who presumably are the hardest to reach, could differ in significant dimensions (Heffetz \& 
Reeves, 2016). Alternatively, other researchers have studied methods to recruit new individuals for the construction of refreshment samples as a means to maintain representativeness and sample size (Chapman, 2003; Dorsett, 2010; Vehovar, 2003; Deng et al, 2013). Yet, again, it is unclear how well refreshment samples correct for potential bias particularly along unobservable characteristics.

A potentially important missing determinant of the probability of panel attrition, linked to relevant survey outcomes, is information related to personality traits. Personality traits like conscientiousness have been found to be predictive of important life outcomes such as education, income and health, and there is some limited evidence that has attempted to link unit nonresponse with personality traits such as conscientiousness or a sense of civic duty or moral obligation in the context of traditional panel datasets (Bosnjak, Tuten, \& Wittmann, 2005, Rogelberg et al., 2003). Our study builds on this literature and aims to study if personality traits comprise a significant predictor, above traditional demographic information and cognitive ability, of panel attrition in the context of an internet panel. To our knowledge this will be the first time that the determinants of panel attrition are studied in the context of an internet panel, as prior work has focused on panel data collected via postal mail, the telephone, or face to face interviewers (Watson \& Wood, 2009). This work then adds to the limited evidence that finds that personality traits could be important determinants of panel attrition.

In addition to obtaining self-reported personality through traditional psychometric scales, we explore the use of paradata as possible proxies for personality traits. Paradata comprise supplementary data that survey administrators collect as part of the data collection process, which is in contrast to data gathered from answers respondents explicitly provide on the questionnaire. Examples of paradata include the time respondents spend completing the survey or number of attempts made to contact a respondent. Such data have become more widely available with the emergence of computer- and internet-based surveys and can be a promising avenue to advance survey research. Indeed, survey research has given increasing attention to this type of data for the purpose of measuring and improving data quality (Kreuter, 2013). We take a different approach and submit that paradata could be viewed as a behavioral measure of personality traits. Prior work suggests that the amount of time respondents spend answering individual items is an indication of conscientiousness (Jensen \& Soland, 2016; Roßmann \& Gummer, 2016; Segal, 2012). Other work has shown that survey effort as measured by item nonresponse or inconsistent answer patterns also captures similar personality traits (Hitt, Trivitt, \& Cheng, 2016; Hitt 2015; Zamarro et al., 2016; Roßmann \& Gummer, 2016). In this paper we study if the number of attempts made to recruit a respondent could be used as a proxy for relevant personality traits found to be related to panel attrition.

We ultimately find that personality and other demographic characteristics both independently explain panel attrition. More specifically, panel attrition is more likely to occur among less conscientious individuals, individuals who are more open to new experiences, and individuals from higher socioeconomic backgrounds. We also show that these patterns hold whether we measure personality traits through traditional psychometric scales or with certain paradata information. However, it is unclear in our data how fully the paradata capture personality traits. Although we show some modest correlations between paradata and traditional measures of personality traits, both types of information independently predict the incidence of panel attrition.

We ultimately suggest that it would be useful for survey researchers to collect measures of personality and to explore the potential of other paradata to be proxies of personality traits. 
Overall, better understanding the nature of unit nonresponse with respect to personality will likely assist survey researchers and practitioners as they address attrition in their panel samples and seek to maintain sound data quality. For example, our findings have theoretical and practical implications for how statistical weights or the construction of refreshment samples can be used to ensure sample representativeness, particularly along dimensions that have not been widely considered before. Improving data quality and survey administration techniques is important as recent work suggests an increase in survey nonresponse rates in the general international population (Brick, \& Williams, 2013; Curtin, Presser, \& Singer, 2005).

This article proceeds as follows. In the next section we present background research on panel attrition, paying particular attention to why personality may influence this occurrence. We then describe the data, key variables of interest, and empirical methods that we use to test our hypotheses. After presenting our results, we conclude with implications for collecting and analyzing panel data.

\section{Background}

\subsection{Sources of Panel Attrition}

Unit nonresponse in survey data is not random, and survey research has dedicated considerable effort to identify causes of unit nonresponse. Some research suggests that unit nonresponse is a function of the techniques that survey administrators utilize. Factors within the control of survey administrators, such as personalizing contacts or increasing follow-up efforts for nonrespondents, affect unit nonresponse rates (Cook, Heath, and Thompson, 2000; Yu \& Cooper 1983). Other scholars have explored the use of monetary incentives and experimented with different types of incentive structures (e.g., prepaid rewards versus rewards conditional on completion) to increase response rates (Church, 1993; Castiglioni et al., 2008; Singer, Hoewyk, \& Maher, 2000; Yu \& Cooper, 1983). Question phrasing, questionnaire formatting, survey mode (e.g., paper versus web) affect unit nonresponse rates as well (Krosnick \& Presser, 2010; Sax, Gilmartin, \& Bryant, 2003; Smith, 1995). All these features of surveys and their administration can be altered to try to mitigate panel attrition.

However, some factors that drive unit nonresponse are outside the control of survey administrators. Research suggests that attrition from traditional panel surveys tends to be more common among respondents from lower socioeconomic backgrounds, with lower levels of education attainment, and those that experience higher levels of mobility (Behr et al., 2005; Fitzgerald, Gottschalk, \& Moffit, 1998; Goyder et al., 2002; Sakshaug \& Huber, 2016). Yet, concerns remain that other unobserved characteristics might be driving decisions of panel attrition, and if these characteristics are linked to relevant survey outcomes, then there would continue to be panel attrition bias.

Personality traits, which are often unobserved, are potential candidates for individual characteristics that can lead to panel attrition bias. Research from economics and psychology has particularly documented the ways in which personality traits affect educational attainment and important life outcomes like health and labor market outcomes. More conscientious individuals are found to have higher levels of educational attainment and greater employment earnings on average, even after controlling for cognitive ability (Almlund et al., 2011). Thus, it is possible that the correlations between panel attrition and educational or labor-market outcomes are partially explained by personality traits. Moreover, there is some limited evidence in survey research that has documented ways in which personality traits along with social or psychological 
factors can influence unit nonresponse. Social norms, a sense of civic duty or moral obligation, and interest in the survey topic all affect the likelihood of responding to a survey (Bosnjak \& Batinic, 2002; Bosnjak, Tuten, \& Wittmann, 2005; Groves, Singer, \& Corning, 2000; Lubin, Levitt, \& Zuckerman, 1962; Marcus \& Shütz, 2005; Rogelberg et al., 2003). In this study, we explicitly model personality traits and examine the extent to which they explain panel attrition. We continue by detailing the measurement of personality traits.

\subsection{Personality Traits and Panel Attrition}

2.2.1 The Big Five personality traits. The Big Five personality traits is a system developed by psychologists to classify broad dimensions of personality (John and Srivastava, 1999). The five traits are openness to experience, conscientiousness, extraversion, agreeableness, and neuroticism. These traits are typically measured by administering validated psychometric scales. Respondents answer to a series of items that are then coded and aggregated to construct self-reported measures of the Big Five personality traits. Each of the Big Five personality traits has been found to affect life outcomes in a variety of ways. For instance, it is well-known that conscientiousness is positively correlated with labor productivity, health, and educational attainment (Almlund et al., 2011; Cubel et al., 2016; MacCann, Duckworth, \& Roberts, 2009; Roberts et al., 2007).

To our knowledge, only two studies have investigated the effect of Big Five personality traits on unit nonresponse. First, Rogelberg et al. (2003) collected baseline data for a population of about 400 undergraduate students from a Midwestern US state, which includes a measure of conscientiousness and agreeableness. The authors then administered two follow-up surveys via mail and found that respondents to the follow up surveys were more conscientious and possibly more agreeable. We extend Rogelberg et al.'s work by conducting a similar analysis on a nationally-representative sample of US adults to test the generalizability of their results. We also obtain measures of all Big Five personality traits in our sample instead of the two that Rogelberg et al. measured to determine if variation in other personality traits explains variation in unit nonresponse. In addition, Rogelberg et al. do not jointly model personality traits with demographic characteristics to examine if one set of variables predicts unit nonresponse net of the other. Nor do they control for intelligence or cognitive ability, which can alter survey response behavior (Krosnick, 1999). Our models explicitly and simultaneously model personality traits, a measure of cognitive ability, and demographic characteristics so that we can parse out their respective, independent contributions to panel attrition, if any. ${ }^{1}$ This analysis is important because if personality traits are found to be predictive of panel attrition above the role of demographic controls, current approaches for correcting for panel attrition bias could be improved if information on relevant personality traits is available. In such a case, using typical demographic information to construct simple weighting schemes or to form refreshment samples may not be sufficient to ensure representativeness and to avoid panel attrition bias.

In a second article that has linked personality to unit nonresponse, Marcus and Schütz (2005) find that individuals who are less agreeable and less open to experience are more likely to

\footnotetext{
${ }^{1}$ Another article by Winefield et al. (1990) demonstrates that respondents with more external locus of control and lower achievement motivation are more likely to attrite from panel datasets. Although this study is not a direct test of the relationship between conscientiousness and unit nonresponse, locus of control is found to be related to conscientiousness and achievement motivation is sometimes considered a facet of conscientiousness (Costa, McCrae, Dye, 1991).
} 
refrain from responding to surveys. This study relies on a selective study sample of owners of personal websites. Among other reasons, this restriction was imposed by the researchers in order to obtain external measures of personality of nonrespondents, which were based upon the observations of independent raters who assessed the content of those personal websites. Whether or not the observers' measures of the Big 5 personality traits are valid is unclear in this study. Although some evidence suggests that self-reported measures of personality traits are fairly correlated with measures based upon independent observers, this is not always the case (Carlson et al., 2011). Certainly, one cannot ascertain the correlations between these two types of measures for nonrespondents who do not provide self-reported measures. We address the limitations in the work by Marcus and Schutz by using data that contains self-reported measures of personality traits for all respondents to an initial survey in a nationally-representative sample.

2.2.2 Paradata as Proxies for Personality. As demonstrated by prior work, researchers face a common data limitation: Self-reported measures of personality traits are not often collected. With respect to panel data, measures of personality are not necessarily collected at baseline, so such data will be unavailable for respondents who exit the sample. In an effort to find ways to address this limitation, we explore the potential of paradata to recover measures of personality traits. Prior work has shown that survey-taking behaviors such as item nonresponse and the supplying of inconsistent answers are driven by personality traits related to conscientiousness (Hitt, Trivitt, \& Cheng, 2016; Hitt, 2015; Segal, 2012; Zamarro et al., 2016). Intuitively, surveys are typically long, low-stakes, mundane tasks. Respondents who lack the conscientiousness to wholeheartedly complete the survey and provide thoughtful answers may shirk by skipping questions, providing invalid answers, or altogether skipping the entire survey. Therefore, it is plausible that information about respondent personality traits lies latent in and can be recovered from paradata.

In fact, there is evidence that indicators of survey effort based upon paradata are predictive of panel attrition. Roßmann \& Gummer (2016) demonstrate that respondents who skip items more frequently or are slow to complete individual items are more likely to not respond to surveys in the future. Other similar work demonstrates that factors that drive item nonresponse or inconsistent answering by respondents on a particular survey may also drive unit nonresponse (Loosveldt, Pickery, \& Billiet, 2002; Yan \& Curtin, 2010). However, these studies do not make an explicit connection between these respondent behaviors and personality traits as we do. We describe our data set and the available paradata in greater detail next.

\section{Data and Methods}

\subsection{Understanding America Study}

Data for this analysis come from the Understanding America Study (UAS) ${ }^{2}$. The UAS is an internet panel administered by the Center for Economic and Social Research based at the University of Southern California. The sample consists of a nationally representative sample of more than 4,000 US households who are asked to complete one to two surveys each month. Individual surveys last approximately 30 minutes, and respondents are compensated for each survey that they complete.

\footnotetext{
${ }^{2}$ For more information visit: http://uasdata.usc.edu.
} 
An important feature of the UAS is its panel structure and the ability to link responses for the same individual across different waves of data collection. To date, most respondents have completed over 30 different surveys, providing a host of information related to personal finance, labor-market outcomes, health, retirement planning, personality, educational background, and cognitive ability.

Respondents in the UAS are recruited through address-based sampling. Any adult willing to participate who does not have a computer or internet access is provided with a tablet and broadband Internet. After an initial letter introducing the UAS, potential respondents receive via postal mail a recruitment package. This package includes a questionnaire, a pre-paid $\$ 5$ incentive, and a promise of $\$ 15$ upon the return of the completed recruitment questionnaire. The end of this questionnaire inquires respondents for interest in participating in the UAS by completing further surveys. A second mail package containing an additional copy of the first recruitment survey is sent within 4 weeks if no response has been received by then. Eventually, respondents who have not completed the recruitment questionnaire after receiving reminders are contacted by phone and asked to complete it at that time. Respondents who have completed the questionnaire receive their promised monetary compensation and those who agreed to be contacted again also receive a welcome package with information to log on to the system to take internet surveys.

Upon logging into the UAS web-site, respondents are asked to give online consent after which they can take the survey entitled My Household. This survey asks for relevant demographic information including gender, age, marital status, education, income, and work status. If respondents declare their interest for participating in the study but do not log into the system to complete the My Household survey within two weeks, they are contacted again with reminders. Three weeks later, if respondents still do not log in and complete the My Household survey, they are given another reminder and offered a final monetary incentive of $\$ 40$ to do so.

After completing My Household all respondents are invited to complete the first official survey named $U A S 1$. Those completing the above described steps are considered active panel members and are invited to complete further surveys. Most respondents continue to take UAS2 after $U A S 1$ but often respondents can choose the order in which they want to take the surveys to which they are invited. Participating respondents get paid for the surveys they take at a rate of $\$ 20$ per 30 minutes (and proportionately less if a survey is shorter). All UAS panel members receive a prepaid debit card, to which new money is added every month depending on how many surveys they have taken.

\subsection{Empirical Strategy}

In our analysis, we rely on the fact that upon accepting the invitation to participate and completing the information in the My Household survey, all respondents first complete UAS1, the first official survey in the UAS. UAS1 includes tests of cognitive ability and psychometric scales designed to obtain measures of the Big Five Personality Inventory. Because respondents are not regularly invited to take other surveys until the point they respond to UAS1, we consider this our starting panel wave and define panel attrition to be zero at this point. Moreover, item response rates within UAS1 are very high, with an average item response rate of 98 percent, perhaps indicating that respondents exerted more care completing this first UAS survey. In later waves of the UAS, item response rates range from 97 percent to as low as 80 percent. Therefore, we assume that information provided in $U A S 1$ possesses a high degree of accuracy about the 
respondent and use it to examine what factors predict survey nonresponse in future waves of the panel.

In particular, we use measures of personality and cognitive ability as collected in UAS1 to determine the extent to which these individual characteristics affect the propensity to respond to a survey in subsequent data collection waves. Regression models all control for cognitive ability ${ }^{3}$ and all available background characteristics that are collected from the My Household survey performed when the respondent initially consents to participate in the UAS. These demographic characteristics include educational attainment, employment status, household income, gender, age, marital status, whether the respondent is foreign born, and racial background. These variables are often predictive of unit nonresponse.

\subsubsection{Dependent Variable}

Our dependent variable is the total number of surveys that the respondent has completed. Because respondents enter the panel at different points in time, at the time of our analysis they might have been invited to a different number of surveys. To correct for this, all of our models control for the total number of surveys that the respondent has been invited to. ${ }^{4}$ Thus, our models will predict the number of surveys completed by respondents conditional upon the number of surveys they have been invited to complete. ${ }^{5}$ Under this framework, panel attrition is more frequent among respondents who have completed fewer surveys. Table 1 displays unit nonresponse rates for each wave of the UAS. For example, 11 percent of respondents in the UAS sample did not complete $U A S 2$ despite being asked to do so. As can be seen in the table, unit nonresponse rates vary widely across the different waves of the UAS. ${ }^{6}$

\section{«Table 1 Here》}

Including UAS1, on average, individual respondents have been invited to about 20 surveys and they complete about 75 percent of them. The distribution of completion rates by individual are displayed in the histogram in Figure 1. Almost 30 percent of respondents complete every survey that they are asked to complete, while approximately 14 percent of respondents do

\footnotetext{
${ }^{3}$ There are two sources of information for cognitive ability in the UAS that we use in this analysis. This information includes the 8-item Lipkus numeracy scale (Lipkus et al., 2001) and responses to a 5-item Cognitive reflection test (Frederick, S., 2005 and Toplak et al., 2014). The cognitive reflection test was developed with the aim to measure a specific type of cognitive ability. In particular, it measures respondent's ability to suppress an intuitive and spontaneous wrong answer in favor of a reflective and deliberative right response. We combine information in these two scales in a unique cognitive ability index using a factor analysis of the total number of correct responses in each of these tests. Both scales are loaded into a unique factor with equal size weights.

${ }^{4}$ Alternatively, we also defined our dependent variable as the percentage of surveys completed among the number the respondent is invited and estimated models using this variable without controlling for the number of surveys that the respondent had been invited to. Results are similar to the ones we present when using the total number of surveys completed while controlling for the number of surveys that the respondent was invited to complete.

${ }^{5}$ Results are not sensitive to whether we linearly model the number of surveys that the respondent has been invited to complete as a single variable or nonlinearly model it as a series of dummy variables. We present results based upon specifications where the number of surveys that a respondent has been invited to is linearly modeled as a single variable.

${ }^{6}$ These numbers should be interpreted with caution, however, as later surveys have been in the field for a shorter period of time. It is then possible that the higher non-response observed in latter waves could be partly due to that shorter time in the field. We unfortunately have no information about the exact time when individual respondents are asked to complete specific surveys. However, we only study response patterns to survey waves that had been in the field for a minimum of 1 week. Moreover, selection into the UAS sample and when someone is selected into the UAS sample are random so any measurement error associated with the measure of unit nonresponse should only make our coefficient estimates less precise, not bias them.
} 
not complete any of them. Despite the prevalence of unit nonresponse, a majority of respondents complete over $90 \%$ of the surveys that they are invited to do.

\subsubsection{Key Independent Variables}

\section{«Figure 1 Here»}

Our key independent variables of interest are measures of personality traits. We first use measures based upon the Big Five framework. The measures of the Big Five personality traits are based on a 44-item scale developed by John, Donahue, and Kentle (1991). Respondents receive a score from 1 to 5 on each of the five dimensions, conscientiousness, agreeableness, neuroticism, extroversion, and openness, based on their responses to each of the 44 items. In the analyses, we standardize our measures of personality trait to have a mean equal to zero and standard deviation equal to one for ease of interpretation. Summary statistics of the raw scale scores and Cronbach's alpha scores for the measures of personality are shown in Table 2. Correlations across the personality measures are also shown and are on par with those found in prior psychological literature (van der Linden, te Nijenhuis, \& Bakker, 2010).

\section{《Table 2 Here》}

We also use various proxies of personality traits derived from paradata. As described earlier, respondents in the UAS receive several reminders at various stages of the recruitment process. Table 3 lists the various efforts to follow up with nonrespondents and the timing of those efforts. For instance, if respondents have not replied to the Recruitment Survey within 4 weeks, a reminder and second Recruitment Survey is sent. Similarly, respondents are reminded to complete the My Household survey if after 2 weeks they have not done so. If respondents still have yet to complete the My Household surveys 3 weeks after receiving the first reminder, they are sent another reminder and given the additional $\$ 40$ monetary incentive to complete it.

\section{《Table 3》}

We posit that differences in personality traits, particularly conscientiousness, explain why some respondents need these reminders while others promptly complete their assigned tasks. We use a series of dummy variables indicating whether or not a respondent received each of these reminders to complete various tasks during the enrollment process as a predictor of panel attrition. Furthermore, we study if the receipt of certain reminders could be used as a proxy for personality traits by examining correlations between these dummy variables and the self-reported measures of the Big Five personality traits.

\section{Results}

Table 4 presents a variety of model specifications to predict the total number of completed surveys (e.g., the frequency with which unit nonresponse does not occur for a respondent). The first specification in column 1 displays estimates of a specification that uses only demographic characteristics to predict panel response rates. This type of specification is typically used in analyses attempting to identify variables that explain panel attrition or to construct nonresponse weights. Individuals with higher levels of cognitive ability, females, respondents born in the US, married individuals, unemployed individuals, individuals with higher incomes, and black individuals are more likely to respond to subsequent waves in the UAS. For instance, all else equal, respondents who are one standard deviation higher on the cognitive ability distribution, respond to about 3 more surveys for every 10 surveys they are asked to complete. Females respond to about five more surveys than males for every 10 surveys they are asked to complete. Differences are of slightly larger magnitude for married versus unmarried and employed versus unemployed respondents - about 6 and 7 surveys for every 10 
surveys they are asked to complete, respectively. Similarly, holding the number of invitations fixed, respondents born in the US complete about one more survey than respondents born outside the US for every survey they are asked to complete. In contrast, those with higher household incomes and lower levels of educational attainment appear to respond to fewer surveys but these estimates are not statistically significant, except for the fact that those in the highest income quartile are more likely than those in the lowest income quartile to miss surveys. Finally, black respondents appear to respond to seven more surveys than white respondents for every 10 they are given.

\section{《Table 4 About Here 》}

Columns 2-6 display estimates that include self-reported measures of personality traits. Net of all the common demographic control variables and cognitive ability, we see that individuals who are more conscientious, less open to experience, and less extroverted tend to complete more surveys. In particular, a one-standard-deviation increase in conscientiousness is associated with respondents completing about 3 more surveys for every 10 surveys they are asked to complete. A similar result is observed for a standard deviation decrease in openness. Finally, a standard deviation decrease in extraversion is associated with about 2 more surveys completed for every 10 a respondent is invited. These results for openness and extraversion are opposite to those found by Marcus and Schütz (2005). We discuss this difference later in the final section.

In addition, it should be noted that in our specifications, coefficient estimates for the demographic variables, except for the variable for age, are generally stable whether or not personality traits are included in the models. Without including measures of personality, age is not a significant predictor of unit nonresponse. Yet by including measures of personality, we see that, all else equal, a respondent who is one year older than another will complete one more survey for every 10 they are asked to do - a result that is now significant at the 0.05 level. There are also some larger fluctuations in the coefficient estimates for employment and marriage status but it is not clear whether the magnitudes are consequential.

Finally, Column 6 displays a specification in which all self-reported measures of personality are jointly included to predict response to future surveys. Conscientiousness and openness to new experience remain predictive of future participation. However, extraversion no longer retains predictive power. This change is due to the shared covariation across the measures of personality, especially between conscientiousness and extraversion and openness and extraversion (see Table 2). Moreover, the coefficient estimate for employed versus unemployed individuals has slightly increased in magnitude.

\section{«Table 5 About Here》}

Turning to the next series of results, we now estimate the same models but use paradata on reminders as potential proxies of personality traits. We begin by presenting estimates linking receipt of reminders to personality traits in Table 5. Each of the coefficient estimates in this table come from models that regress a given personality trait on dummy variables that indicate whether the respondent received a particular reminder or not. Consider the top panel, in Column 1 , we see that receiving a reminder for completing the very initial Recruitment Survey does not seem to be correlated with either conscientiousness or openness to experience, the two personality traits that were found to be most related to panel attrition in our analysis above. Receiving a reminder to complete the Recruitment Survey appears to be only marginally related to neuroticism. There are several reasons why this early reminder might not be a good proxy for personality traits. First, having to receive a first reminder seems a common practice and a big 
majority of respondents (about 80\%) end up receiving one in the UAS. In addition, paradata for this first reminder might be of lower quality than the data collected in subsequent reminders. At this early stages of the respondents' recruitment process data collection on reminders required more manual data entry than on later reminders, once respondents are given access to the system through internet. Therefore, this first paradata variable on reminders is potentially more prone to measurement error. In contrast, later reminders seem to be better proxies for personality traits related to panel attrition. In Column 2, those who received one and two reminders to complete the My Household survey, rank about 0.07 and 0.10 standard-deviation units lower in conscientiousness, respectively. However, these results are not statistically distinguishable from zero at conventional levels. To increase statistical power, we combine these dummy variables and run a model that compares respondents who received any number of reminders to complete My Household survey to those who did not. The result is shown in column 3. As can be observed, respondents who received any reminder to complete My Household survey rank about 0.08 standard-deviation units $(\mathrm{p}<0.1)$ lower in conscientiousness than those who did not receive reminders. Columns 4-6 report estimates of the same regressions but also controlling for demographic characteristics. Results are similar to models without control variables, though now the difference in conscientiousness between respondents who receive and did not receive reminders to complete My Household survey is slightly larger and statistically significant.

Taking a look at the bottom two panels that examine the relationship between openness to experience and extraversion, we see similar patterns for comparisons of respondents who received or did not receive reminders to complete the My Household survey. In general, respondents who received reminders appear to be more open to experience and are more extraverted. Finally, there do not appear to be differences across individuals who received or did not receive reminders in levels of agreeableness or neuroticism (see the second and third panels of Table 5).

\section{《Table 6 About here》}

That said, we do observe that respondents who receive reminders are less likely to complete subsequent surveys. As seen in Column 1 of Table 6, respondents who had received reminders to complete the Recruitment Survey complete about 0.4 fewer surveys than those who did not receive those reminders. In column 3, we see that the effect of later reminders is much bigger; respondents who must be reminded once to complete the My Household survey complete about 4 fewer surveys than those who receive no reminders, as are those who must be reminded twice to complete the My Household survey. Curiously, these results are robust to including measures of personality traits jointly with the paradata. Even the self-reported measures of conscientiousness and openness to experience retain their power to predict whether respondents will respond to future surveys. This suggests that, although somewhat related to conscientiousness and openness to experience, these paradata on reminders might also capture other relevant circumstances of the respondents that predict future survey participation. Notably, coefficient estimates for the demographic characteristics also largely remain unchanged. We further discuss the implications of these findings next.

\section{Discussion and Conclusion}

To summarize, we predict unit nonresponse in an internet panel representative of US adults, once they have consented to participate and completed two initial baseline surveys (i.e., My Household and UAS1). We find unit nonresponse is more prevalent among individuals who are less conscientious, more open to experience, male, older, foreign born, unmarried, and come 
from higher socioeconomic backgrounds as measured by employment and earnings. We do not find that unit nonresponse is more or less prevalent among highly educated individuals and find some evidence that relative to white individuals, black individuals are more likely to respond to subsequent surveys.

With the exception of socioeconomic status, these findings generally comport with those of prior work which studied panel attrition among telephone or face-to-face interview surveys (Behr et al., 2005; Bosnjak, Tuten, \& Wittmann, 2005; Goyder, Warriner, \& Miller, 2002; Rogelberg et al., 2003; Sakshaug \& Huber, 2016). That said, some scholars have maintained that panel attrition and socioeconomic status is not a linear relationship, stating that unit nonresponse rates are higher along the tails of the socioeconomic distribution (Watson \& Wooden, 2009). We do not find this quadratic relationship in our internet panel dataset as response rates for individuals in the lowest quartile of household income are not statistically distinguishable from those in the second and third quartiles. If anything, the coefficients depict a linear relationship with higher income-earners being less likely to respond to surveys. It is possible that the higher rates of unit nonresponse among respondents form higher socioeconomic backgrounds are due to the nature of the UAS. Findings that unit nonresponse is higher among respondents from lower socioeconomic backgrounds occur in surveys that have lower capacity to track these respondents. Specifically, these surveys rely on reaching respondents through their place of residence, making it difficult to follow families from lower socioeconomic backgrounds, who are highly mobile (Behr et al., 2005; Goyder et al., 2002). In contrast, the UAS maintains contact with its sample members through the internet and even provides internet service and hardware for those who cannot afford it. Moreover, the UAS compensates its respondents for completing surveys. It is possible that the compensation not only incentivizes respondents from lower socioeconomic backgrounds to complete surveys but also is lower than the opportunity cost of completing surveys among respondents from higher socio-economic backgrounds. More work investigating this pattern will be worthwhile, especially as new technology is utilized to collect data and to follow respondents longitudinally.

In summary, we underscore the importance of considering personality traits as factors that potentially explain unit nonresponse in survey data. It is not enough to merely identify demographic characteristics such as income or educational background as reasons for nonresponse because personality traits may independently affect nonresponse behavior. Typically-available demographic characteristics might not control for all differences among respondents and nonrespondents. If so, simple reweighting approaches would not fully correct for panel attrition bias. Indeed, when predicting unit nonresponse, coefficient estimates of demographic characteristics are generally not sensitive to the inclusion of personality traits, but this is not always so as in the case of age. Of course, one would technically need to construct weights based on models with and without personality traits to determine how well each model corrects possible nonresponse bias. Unfortunately, we are unable to conduct such a test because we lack outcome data for nonrespondents in the UAS.

More generally, our results demonstrate that personality information might be a key missing variable leading to panel attrition bias. We have shown that conscientiousness and openness to experience independently predict panel attrition, even after controlling for cognitive ability and demographic characteristics. These results track with Rogelberg et al. (2003) who also found that conscientiousness was a driver of survey completion among undergraduate students. However, our results for extraversion and openness to experience described above are opposite to results found by Marcus and Schütz (2005) among web users. This previous research 
found that those web users with higher levels of extraversion and openness to experience more often indicated the willingness to participate in a follow up survey. Although very different survey samples could explain differences between our results and theirs, it is also likely that selfreports are different from actual behavior. Respondents who are more open to experience or extraverted may be more likely to say that they are willing to participate in follow-up surveys yet, in reality, be less likely to actually do so, especially if they are willing to participate in more activities overall.

Importantly, previous research literature has highlighted the independent effect of personality on multiple life outcomes. Conscientiousness and openness to new experience, in particular, independently explain the incidence of panel attrition as well as later-life outcomes (Almlund et al., 2011; Heckman \& Rubinstein, 2001; Heckman, Stixrud, \& Urzua, 2008). Providing this more accurate picture of unit nonresponse has theoretical and practical implications. We advise that survey practitioners collect personality early on in panel datasets and to use this information to potentially improve statistical weights for addressing panel attrition bias later on. Based on our results, incorporating such information into these weights could address potential nonresponse bias more fully than including demographic information alone. We encourage future research to examine this topic.

Of course, measures of personality traits are not always available in existing data sets. In such cases, we point out that proxies of personality traits could be latent in the data and as such may potentially be derived from paradata. We show that respondents who required reminders to complete a particular survey in our data are less conscientious, more open to experience, and more extraverted. We warn, however, that not all paradata on reminders might be good proxies for relevant personality traits and that the quality of such paradata and timing of the reminder might be relevant for its viability as an appropriate proxy. In our analysis, correlations between our paradata and self-reported measures of personality are modest in several cases. We have also found that later reminders to complete My Household survey appear to be better proxies than the earlier reminder to complete the Recruitment Survey is not. Again, more research into the viability of paradata to proxy personality traits or other circumstances would be valuable.

Yet even then, our results also indicate that self-reported personality traits still predict the likelihood of responding to subsequent surveys even after including paradata measures into our models. Both personality traits and reminders at recruitment remain statistically significant predictors of future survey completion. This suggests that a significant proportion of the relevant variation in self-reported measures of personality traits remain unaccounted for with the proxies that we test and that paradata on reminders might capture other individual circumstances related to survey taking behavior. More research would be needed to obtain a better understanding of what paradata is capturing and what types of paradata can effectively substitute for otherwise unobserved respondent characteristics. Indeed, other research has linked survey-taking behavior to personality traits (Hitt et al., 2016; Hitt, 2015; Zamarro et al., 2016), while other survey research has documented a relationship between panel attrition to other types of paradata such as item nonresponse rates and time spent on the questionnaire (Roßmann \& Gummer, 2016). Until this analysis, however, the proposition that paradata on reminders could capture important personality traits related to the likelihood of panel attrition had not yet been explicitly documented in survey research. We encourage researchers to ponder what respondent characteristics can be actually recovered from paradata.

Along these lines, recent research has started to investigate the use of paradata to improve sample weights or other statistical methods aiming to reduce panel attrition bias. Still, it is not 
clear to what extent bias can be addressed by paradata, or if using paradata is even warranted in the first place (Behaghel et al., 2015; Heffetz \& Reeves, 2016; Wagner et al., 2014). We propose that our explicit link between personality traits and panel attrition provides some theoretical guidance for the potential of paradata to improve the analysis of survey data and corrections for sample bias. That is, statistical corrections aimed at addressing panel attrition bias could be improved with the inclusion of paradata insofar as the paradata capture personality traits that are relevant for particular outcomes. Such theoretical guidance could inform survey researchers how to effectively incorporate paradata into sample weights in a way that reduces bias instead of merely adding statistical noise. For instance, analyses that include outcome variables that are known to be influenced by particular personality traits may wish to include measures of personality - whether they are self-reported measures or proxied by paradata — to address panel attrition bias. Thinking more clearly about the causes of panel attrition and how data can be leveraged to address potential bias will likely improve research efforts in the social sciences. 


\section{References}

Almlund, M., Duckworth, A.L., Heckman, J.J., \& Kautz, T.D. (2011). Personality Psychology and Economics. In E. A. Hanushek, S. Machin, \& L. Woessmann (Eds.), Handbook of the Economics of Education, 1-181. Amsterdam: Elsevier.

Becker, G. Human capital; a theoretical and empirical analysis, with special reference to education. New York: Columbia University Press, 1964.

Behaghel, L., Crepon, B., Gurgand, M., \& Le Barbanchon, T. (2015). Please call again: Correcting nonresponse bias in treatment effect models. The Review of Economics and Statistics, 97(5), 1070-1080.

Behr, A., Bellgardt, E., \& Rendtel, U. (2005). Extent and determinants of panel attrition in the European Community Household Panel. European Sociological Review, 21(5), 489-512.

Bosnjak, M., \& Batinic, B. (2002). Understanding the willingness to participate in onlinesurveys. In B. Batinic, U.D. Reips, \& M. Bosnjak (Eds.), Online Social Sciences, (pp. 8192). Seattle, WA: Hogrefe \& Huber.

Bosnjak, M., Tuten, T.L., \& Wittman, W.W. (2005). Unit (non)response in web-based access panel surveys: An extended planned-behavior approach. Psychology and Marketing, 22(6), 489-505.

Brick, J.M., \& Williams, D. (2013). Explaining rising nonresponse rates in cross-sectional surveys. ANNALS of the American Academy of Political and Social Science, 645(1), 3659.

Calinescue, M., \& Schouten, B. (2016). Adaptive survey designs for nonresponse and measurement error in multipurpose surveys. Survey Research Methods, 10(1), 35-47.

Carlson, E. N., Vazire, S., \& Furr, R. M. (2011). Meta-insight: Do people really know how others see them? Journal of Personality and Social Psychology, 101(4), 831-846

Catigloino, L., Pforr, K., \& Krieger, U. (2008). The effect of incentives on response rates and panel attrition: Results of a controlled experiment. Survey Research Methods, 2(3), 151158.

Chapman, D.W. (2003). To substitute or not to substitute - that is the question. The Survey Statistician, 48, 32-34.

Cook, C., Heath, F., \& Thompson, R. L. (2000). A meta-analysis of response rates in Web- or Internet-based surveys. Educational and Psychological Measurement, 60(6), 821-836.

Costa, P.T., McCrae, R.R, \& Dye, D.A. (1991). Facet scales for agreeableness and conscientiousness: A Revision of the NEO Personality Inventory.

Cubel, M., Nuevo-Chiquero, A., Sanchez-Pages, S., \& Vidal-Fernandez, M. (2016). Do personality traits affect productivity? Evidence from the laboratory. The Economic Journal, 126, 592, 654-681.

Curtin, R., Presser, S., \& Singer, E. (2005). Changes in telephone survey nonresponse over the past quarter century. Public Opinion Quarterly, 69(1), 87-98.

Deng, Y., Hillygus, D. S., Reiter, J.P., Si Y., \& Zheng, S. (2013). Handling attrition in longitudinal studies: The case for refreshment samples. Statistical Science, 28(2), 238256.

Dorsett, R. (2010). Adjusting for nonignorable sample attrition using survey substitutes identified by propensity score matching: An empirical investigation using labour market data. Journal of Official Statistics, 26(1), 105-125.

Frederick, S. (2005). Cognitive reflection and decision making. The Journal of Economic Perspectives, 19(4), 25-42. 
Fitzgerald, J., Gottschalk, P., Moffitt, R. (1998). The Impact Of attrition in the panel study of income dynamics on intergenerational analysis. Journal of Human Resources, 33(2), 300344.

Goyder, J., Warriner, K., Miller, S. (2002). Evaluating socio-economic status (SES) bias in survey nonresponse. Journal of Official Statistics, 18(1), 1-11.

Groves, R. M., Cialdini, R. B., \& Couper, M. P. (1992). Understanding the decision to participate in a survey. Public Opinion Quarterly, 56, 475-495.

Heckman, J.J., \& Rubinstein, Y. (2001). The importance of noncognitive skills: Lessons from the GED testing program. American Economic Review, 91(2), 145-149.

Heckman, J.J., Stixrud, J., \& Urzua, S. (2006). The effects of cognitive and noncognitive abilities on labor market outcomes and social behavior. Journal of Labor Economics, 24(3), 411482.

Heffetz, O., \& Reeves, D. B. (2016). Difficulty to reach respondents and nonresponse bias: Evidence from large government surveys. NBER Working Paper Series, w22333.

Hitt, C.E. (2015). Just filling in the bubbles: Using careless answer patterns on surveys as a proxy measure of noncognitive skills (EDRE Working Paper 2015-06). Fayetteville, AR: Department of Education Reform, University of Arkansas.

Hitt, C.E., Trivitt, J.R., Cheng, A. (2016). When you say nothing at all: The predictive power of student effort on surveys. Economics of Education Review, 52, 105-119.

Jensen, N., \& Soland, J. (2016). Undersatnding the impact of student test effort on teacher-value added estimates. Paper presented at the Association for Education Finance and Policy 41st Annual Conference, March 17-19. Denver, CO.

John, O.P., \& Srivastava, S. (1999). The Big Five trait taxonomy: History, measurement, and theoretical perspectives. In L. Pervin, \& O.P. John (Eds.), Handbook of personality: Theory and Research (2nd Ed.), (pp. 102-138). New York: Guilford.

John, O. P., Donahue, E. M., \& Kentle, R. L. (1991). The Big Five Inventory--Versions 4a and 54., Institute of Personality and Social Research. Berkeley, CA: University of California, Berkeley

Korbmacher, J.M., \& Schroeder, M. (2013). Consent when linking survey data with administrative records: The role of the interviewer. Survey Research Methods, 7(2), 115131.

Kreuter, F. (2013). Improving surveys with paradata: Analytic uses of process information. Hoboken, NJ: John Wiley \& Sons, Inc.

Krosnick, J.A., \& Presser, S. (2010). Question and questionnaire design.” In P.V. Mardsen, \& J.D. Wright (Eds.), Handbook of Survey Research (2nd ed) (pp. 263-314) Bingley, UK: Emerald Group Publishing Limited.

Lipkus, I.M., Samsa, G., \& Rimer, B.K. (2001). General performance on a numeracy scale among highly educated samples. Medical Decision Making, 21(1), 37-44.

Loosveldt, G., Pickery, J., \& Billet, J. (2002). Item nonresponse as a predictor of unit nonresponse in a panel survey, 18(4), 545-557.

Lynn, P. (2013). Alternative sequential mixed-mode designs: Effects on attrition rates, attrition bias, and costs. Journal of Survey Statistics and Methodology, 1(2), 183-205.

MacCann, Carolyn, Angela L. Duckworth, and Richard D. Roberts, 2009. "Empirical Identification of the Major Facets of Conscientiousness." Learning and Individual Differences 19(4), 451-458. 
Marcus, B., \& Schütz, A. (2005). Who are the people reluctant to participate in research? Personality correlates of four different types of nonresponse as inferred from self- and observer ratings. Journal of Personality, 73(4), 959-984.

Mirowsky, J., \& Reynolds, J.R. (2000). Age, depression, and attrition in the National Survey of Families and Households. Sociological Methods and Research, 28(4), 476-504.

Puma, M., Olsen, R.B., Bell, S.H., \& Price, C. (2009). What to do when data are missing in group randomized controlled trials (NCEE 2009-0049). Washington, DC. US Department of Education.

Roberts, B. W., Harms, P. D., Caspi, A., \& Moffitt, T. E. (2007). Predicting the counterproductive employee in a child-to-adult prospective study. Journal of Applied Psychology, 92(5), 1427-1436.

Rogelberg, S., Conway, J., Sederburg, M., Spitzmüller, C., Aziz S., Knight, W. (2003). Profiling Active and Passive Nonrespondents to an Organizational Survey. Journal of Applied Psychology, 88(6):1104-1114.

Sakshaug J.W., \& Huber, M. (2016). An evaluation of panel nonresponse and linkcage consent bias in a survey of employees in Germany, Journal of Survey Statistics and Methodology, 4, 71-93.

Sax, L.J., Gilmartin, S.K., Bryant, A.N. (2003). Assessing response rates and nonresponse bias in web and paper surveys. Research in Higher Education, 44(4), 409-432.

Schifeling, T.A., Cheng, C., Reiter, J.P., \& Hillygus, D.S. (2015). Accounting for nonignorable unit nonresponse and attrition in panel studies with refreshment samples. Journal of Survey Statistics and Methodology, 3(3), 265-295.

Segal, C. (2012). Working when no one is watching: Motivation, test scores, and economic success. Management Science, 58(8), 1438-1457.

Singer, E., van Hoewyk, J. V., Gebler, N., Raghunathan, T., \& McGonagle, K. (1999). The Effect of Incentives on Response Rates in Interviewer-Mediated Surveys. Journal of Official Statistics, 15(2), 217-230.

Smith, T.W. (1995). Little things matter: A sampler of how differences in questionnaire format can affect survey responses." In Proceedings of the American Statistical Association, Survey Research Methods Section, 1046-51. Alexandria, VA: American Statistical Association.

Toplak, Maggie E., Richard F. West, and Keith E. Stanovich., 2014. "Assessing Miserly Information Processing: An Expansion of the Cognitive Reflection Test." Thinking \& Reasoning 20(2), 147-168.

Twisk, J., \& de Vente, W. (2002). Attrition in longitudinal studies: How to deal with missing data. Journal of Clinical Epidemiology, 55(4), 329-337.

Wagner, J., Valliant, R., Hubbard, F., \& Jiang, L. (2014). Level-of-effort paradata and nonresponse adjustment models for a national face-to-face survey. Journal of Survey Statistics and Methodology, 2(4), 401-432.

Watson, N., \& Wooden, M. (2009). Identifying factors affecting longitudinal survey response. In P. Lynn (Ed.), Methodology of Longitudinal Surveys, pp. 157-182. John Wiley \& Sons, Ltd, Chichester, UK.

Winefield, A. H., Winefield, H. R., \& Tiggemann, M. (1990). Sample attrition bias in a longitudinal study of young people. Australian Journal of Psychology, 42(1), 75-85. 
van der Linden, D., te Nijenhuis, J., Bakker, A.B. (2010). The general factor of personality: A meta-analysis of Big Five intercorrelations and criterion-related validity study. Journal of Research in Personality, 44(3), 317-327.

Vehovar, V. (2003). Field substitutions revisited. The Survey Statistician, 48, 35-37.

Yan, T., \& Curtin, R. (2010). The relation between unit nonresponse and item nonresponse: A response continuum perspective. International Journal of Public Opinion Research, 22(4), 535-551.

Zamarro, G., Cheng, A., Shakeel, M., \& Hitt, C. (2016). Comparing and validating measures of character skills: Findings from a nationally representative sample (EDRE Working Paper 2016-08). Fayetteville, AR: Department of Education Reform, University of Arkansas. 
Table 1: Unit Nonresponse Rates across Waves of UAS

\begin{tabular}{|c|c|c|c|}
\hline $\begin{array}{l}\text { Survey } \\
\text { Wave }\end{array}$ & $\begin{array}{l}\text { Number of Respondents } \\
\text { Invited to Survey Wave }\end{array}$ & $\begin{array}{c}\text { Number of Invitees } \\
\text { Completing Survey Wave }\end{array}$ & $\begin{array}{c}\text { Unit Nonresponse } \\
\text { Rate }(\%)\end{array}$ \\
\hline UAS1 & 3,694 & 3,694 & 0.00 \\
\hline UAS2 & 3,418 & 3,028 & 11.41 \\
\hline UAS3 & 1,118 & 1,026 & 8.23 \\
\hline UAS4 & 1,995 & 1,592 & 20.20 \\
\hline UAS5 & 1,740 & 1,491 & 14.31 \\
\hline UAS6 & 3,328 & 2,885 & 13.31 \\
\hline UAS7 & 1,457 & 1,046 & 28.21 \\
\hline UAS8 & 411 & 358 & 12.90 \\
\hline UAS9 & 1,843 & 1,472 & 20.13 \\
\hline UAS10 & 200 & 100 & 50.00 \\
\hline UAS11 & 1,756 & 1,227 & 30.13 \\
\hline UAS12 & 1,874 & 1,361 & 27.37 \\
\hline UAS13 & 65 & 57 & 12.31 \\
\hline UAS14 & 1,116 & 703 & 37.01 \\
\hline UAS15 & 2,147 & 1,760 & 18.03 \\
\hline UAS16 & 2,991 & 2,424 & 18.96 \\
\hline UAS17 & 1,848 & 1,521 & 17.69 \\
\hline UAS18 & 3,048 & 2,527 & 17.09 \\
\hline UAS19 & 703 & 637 & 9.39 \\
\hline UAS20 & 3,220 & 2,676 & 16.89 \\
\hline UAS21 & 2,507 & 2,387 & 4.79 \\
\hline UAS22 & 2,282 & 2,139 & 6.27 \\
\hline UAS23 & 1,850 & 1,766 & 4.54 \\
\hline UAS24 & 2,029 & 1,920 & 5.37 \\
\hline UAS25 & 1,694 & 1,625 & 4.07 \\
\hline UAS26 & 2,976 & 2,271 & 23.69 \\
\hline UAS27 & 1,751 & 1,389 & 20.67 \\
\hline UAS28 & 1,893 & 1,407 & 25.67 \\
\hline UAS30 & 1,639 & 1,277 & 22.09 \\
\hline UAS31 & 2,230 & 1,572 & 29.51 \\
\hline UAS32 & 1,929 & 1,458 & 24.42 \\
\hline UAS36 & 2,491 & 1,718 & 31.03 \\
\hline UAS37 & 899 & 433 & 51.84 \\
\hline UAS38 & 2,795 & 2,043 & 26.91 \\
\hline UAS39 & 847 & 710 & 16.17 \\
\hline UAS40 & 3,309 & 2,530 & 23.54 \\
\hline UAS45 & 357 & 165 & 53.78 \\
\hline UAS47 & 3,252 & 1,700 & 47.72 \\
\hline
\end{tabular}

Note: Response rates may vary depending on how long each survey has been in the field. At the time of our analysis, most respondents had ample time to respond to surveys. 
Table 2: Summary Statistics and Correlations for Personality Traits

\begin{tabular}{|c|c|c|c|c|c|c|c|c|}
\hline \multirow[b]{2}{*}{ Personality Trait } & \multirow[b]{2}{*}{ Mean } & \multirow{2}{*}{$\begin{array}{l}\text { Standard } \\
\text { Deviation }\end{array}$} & \multirow{2}{*}{$\begin{array}{c}\text { Coefficient } \\
\text { Alpha }\end{array}$} & \multicolumn{5}{|c|}{ Correlation Matrix } \\
\hline & & & & $\begin{array}{l}\text { Conscientiousnes } \\
\text { s }\end{array}$ & $\begin{array}{c}\text { Agreeablene } \\
\text { ss }\end{array}$ & $\begin{array}{c}\text { Neuroticis } \\
\mathrm{m}\end{array}$ & $\begin{array}{c}\text { Opennes } \\
\text { s }\end{array}$ & $\begin{array}{c}\text { Extraversio } \\
\mathrm{n}\end{array}$ \\
\hline $\begin{array}{l}\text { Conscientiousne } \\
\text { ss }\end{array}$ & 4.05 & 0.62 & 0.77 & 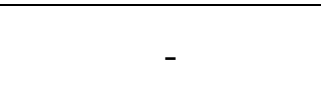 & & & & \\
\hline Agreeableness & 4.03 & 0.60 & 0.74 & 0.40 & - & & & \\
\hline Neuroticism & 2.65 & 0.81 & 0.82 & -0.42 & -0.38 & - & & \\
\hline Openness & 3.64 & 0.64 & 0.77 & 0.24 & 0.21 & -0.20 & - & \\
\hline Extraversion & 3.33 & 0.80 & 0.82 & 0.25 & 0.21 & -0.31 & 0.33 & - \\
\hline
\end{tabular}

Note: Scale scores range from 1 to 5 . Higher values indicate higher levels of a personality trait. 
1. Respondents receive recruitment questionnaire

2. Respondents who have not completed the recruitment questionnaire are sent reminders (Reminded to Complete the Recruitment Survey)

4 weeks after 1

3. Respondents who express interest in participating in UAS per their reply on the recruitment questionnaire are asked to complete the My Household Survey

4. Respondents who have not completed the My Household Survey receive a first reminder to complete it (Reminded 2 weeks after 3 Once to Finish "My Household")

5. Respondents who have not completed the My Household Survey receive a second reminder and an additional monetary incentive to complete it (Reminded Twice to Finish "My Household") 
Table 4: The Influence of Personality (based on Self-Reported Measures) on Panel Attrition

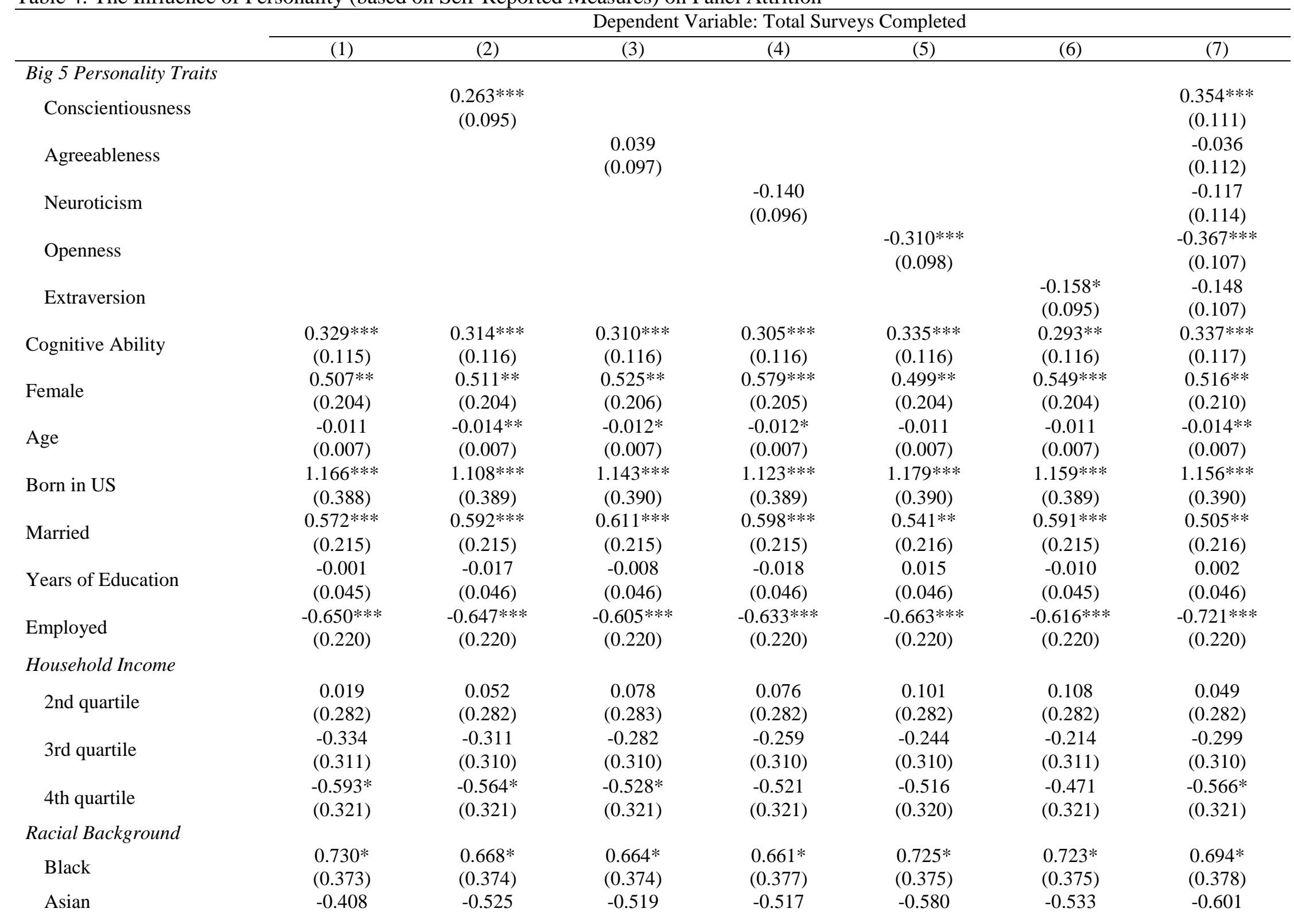




\begin{tabular}{|c|c|c|c|c|c|c|c|}
\hline \multirow{3}{*}{ Native American } & $(0.726)$ & $(0.726)$ & $(0.727)$ & $(0.726)$ & $(0.726)$ & $(0.726)$ & $(0.724)$ \\
\hline & -0.538 & -0.605 & -0.627 & -0.687 & -0.667 & -0.655 & -0.684 \\
\hline & $(0.625)$ & $(0.625)$ & $(0.626)$ & $(0.625)$ & $(0.624)$ & $(0.624)$ & $(0.625)$ \\
\hline \multirow{2}{*}{ Pacific Islander/Hawaiian } & -1.707 & -1.778 & -1.776 & -1.825 & -1.666 & -1.750 & -1.649 \\
\hline & (1.967) & $(1.956)$ & (1.958) & (1.954) & (1.954) & $(1.955)$ & (1.949) \\
\hline \multirow{2}{*}{ Hispanic } & -0.563 & -0.427 & -0.395 & -0.422 & -0.358 & -0.384 & -0.405 \\
\hline & $(0.431)$ & $(0.335)$ & $(0.335)$ & $(0.336)$ & $(0.335)$ & $(0.335)$ & $(0.336)$ \\
\hline \multirow{2}{*}{ Mixed Race } & -0.357 & -0.618 & -0.607 & -0.631 & -0.536 & -0.615 & -0.564 \\
\hline & $(0.335)$ & $(0.431)$ & $(0.431)$ & $(0.431)$ & $(0.431)$ & $(0.431)$ & $(0.430)$ \\
\hline Observations & 3,393 & 3,375 & 3,377 & 3,374 & 3,370 & 3,373 & 3,366 \\
\hline R-Squared & 0.748 & 0.749 & 0.748 & 0.749 & 0.749 & 0.749 & 0.751 \\
\hline
\end{tabular}

Notes. Models also control for the number of surveys that respondents were asked to complete. Omitted category in Household Income are respondents in the first (i.e., lowest) quartile of household income. Omitted Category for Racial Background is white respondents. $* * * p<0.01, * *$ $\mathrm{p}<0.05, * \mathrm{p}<0.1$ 
Table 5: Relationship between Personality Traits and Receipt of a Reminder

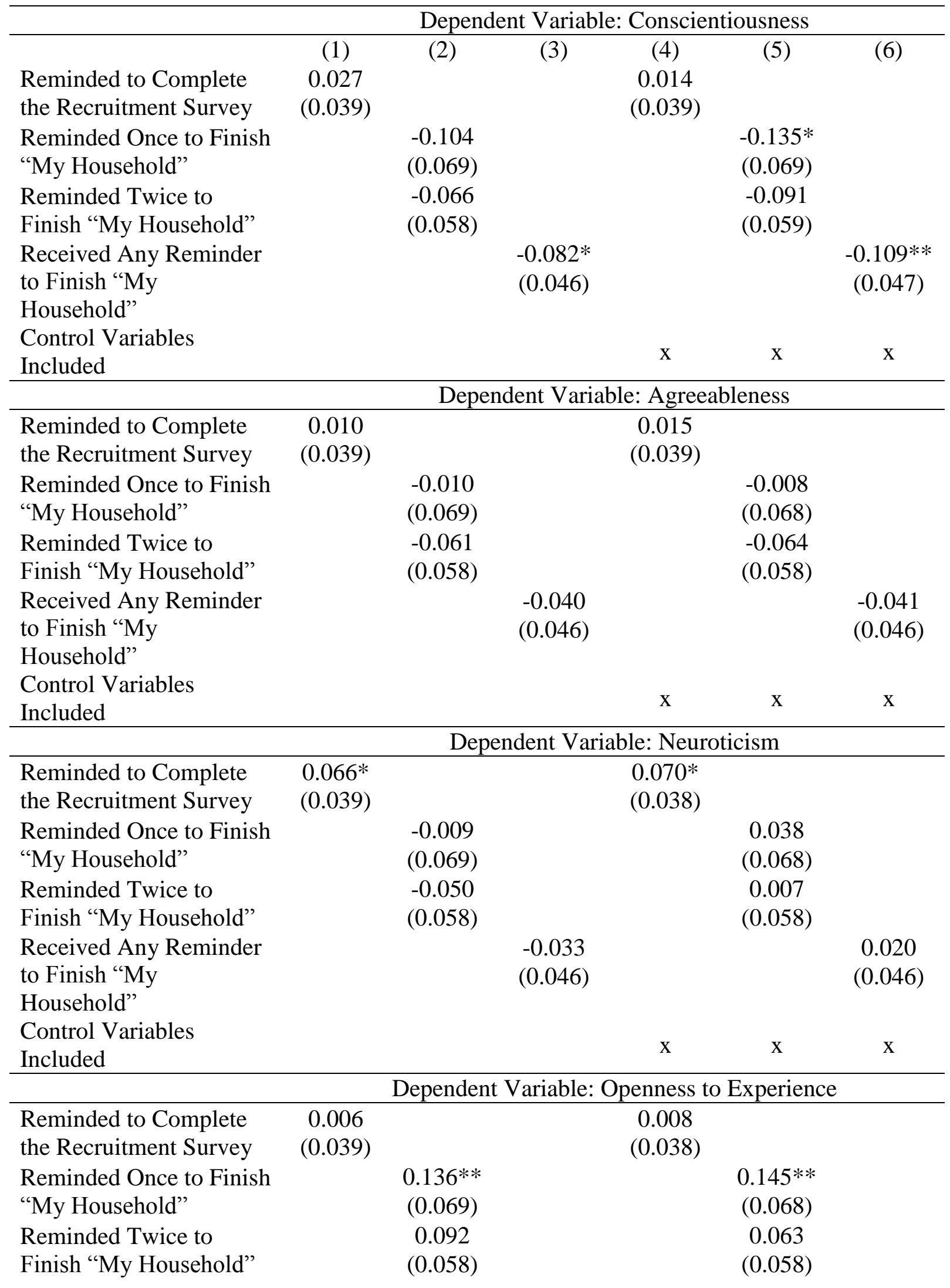




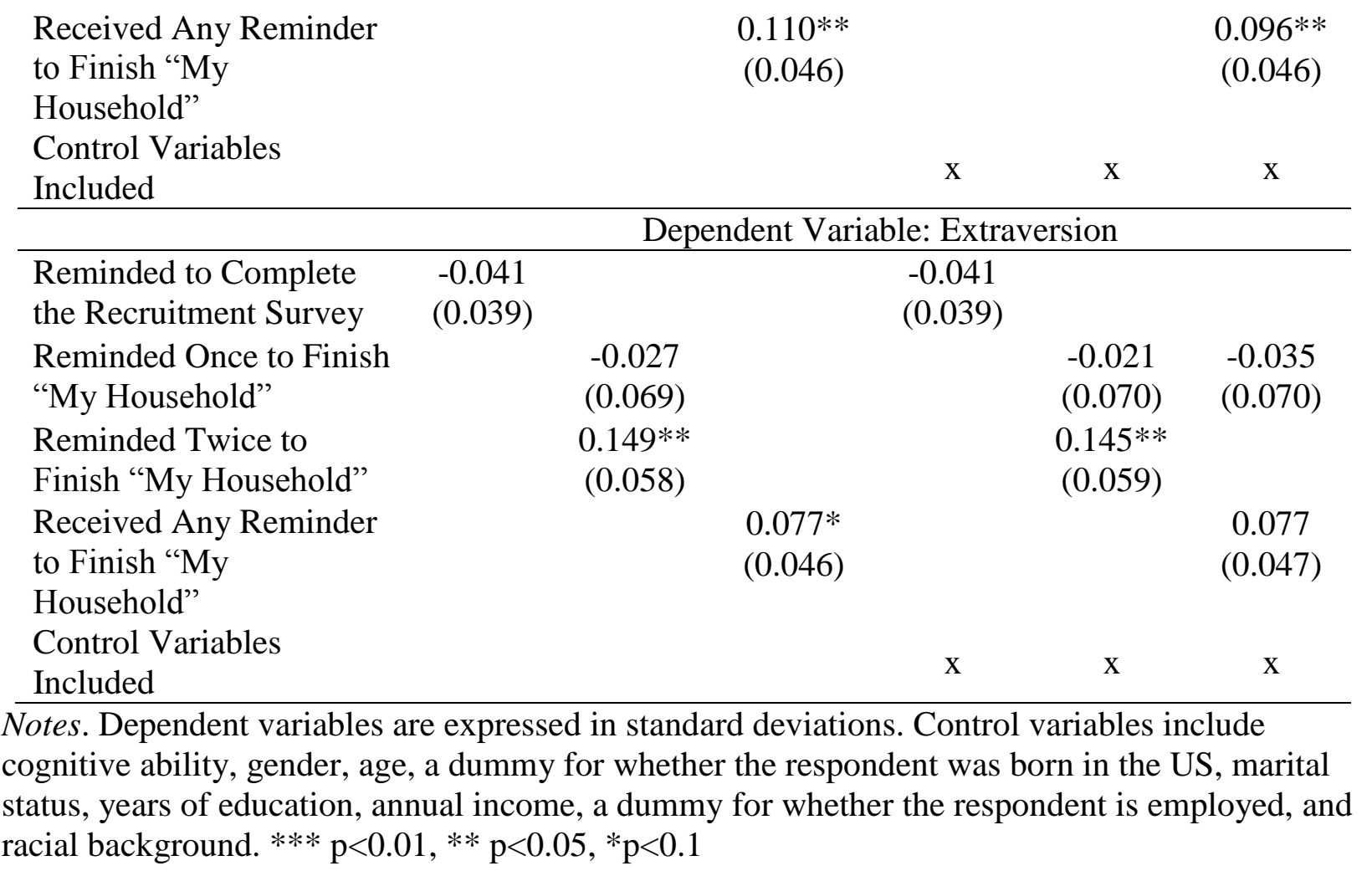


Table 6: The Influence of Personality (as Proxied by Paradata) on Panel Attrition

\begin{tabular}{|c|c|c|c|c|}
\hline & \multicolumn{4}{|c|}{ Dependent Variable: Total Surveys Completed } \\
\hline & (1) & (2) & (3) & (4) \\
\hline \multicolumn{5}{|l|}{ Paradata Proxies of Personality } \\
\hline \multicolumn{5}{|l|}{ Traits } \\
\hline Received Reminder to Complete & $-0.442 *$ & $-0.478 * *$ & & \\
\hline Recruitment Survey & $(0.225)$ & $(0.225)$ & & \\
\hline Reminded Once to Finish "My & & & $-3.919 * * *$ & $-3.743 * * *$ \\
\hline Household" & & & $(0.395)$ & $(0.397)$ \\
\hline Reminded Twice to Finish "My & & & $-4.054 * * *$ & $-3.909 * * *$ \\
\hline Household" & & & $(0.340)$ & $(0.341)$ \\
\hline \multicolumn{5}{|l|}{ Big 5 Personality Traits } \\
\hline Conscientiousness & & $\begin{array}{c}0.359 * * * \\
(0.110)\end{array}$ & & $\begin{array}{c}0.284 * * * \\
(0.108)\end{array}$ \\
\hline Agreeableness & & $\begin{array}{l}-0.035 \\
(0.112)\end{array}$ & & $\begin{array}{c}-0.038 \\
(0.109)\end{array}$ \\
\hline Neuroticism & & $\begin{array}{l}-0.108 \\
(0.114)\end{array}$ & & $\begin{array}{l}-0.128 \\
(0.110)\end{array}$ \\
\hline Openness & & $\begin{array}{c}-0.367^{* * * *} \\
(0.107)\end{array}$ & & $\begin{array}{c}-0.324 * * * * \\
(0.104)\end{array}$ \\
\hline Extraversion & & $\begin{array}{l}-0.148 \\
(0.107)\end{array}$ & & $\begin{array}{l}-0.106 \\
(0.104)\end{array}$ \\
\hline Cognitive Ability & $\begin{array}{c}0.328 * * * \\
(0.115)\end{array}$ & $\begin{array}{c}0.338^{* * * *} \\
(0.117)\end{array}$ & $\begin{array}{c}0.223 * * \\
(0.112)\end{array}$ & $\begin{array}{c}0.245^{* *} \\
(0.114)\end{array}$ \\
\hline Female & $\begin{array}{c}0.505^{* *} \\
(0.204)\end{array}$ & $\begin{array}{c}0.514^{* *} \\
(0.210)\end{array}$ & $\begin{array}{l}0.357^{*} \\
(0.198)\end{array}$ & $\begin{array}{l}0.386^{*} \\
(0.204)\end{array}$ \\
\hline Age & $\begin{array}{c}-0.011 \\
(0.007)\end{array}$ & $\begin{array}{c}-0.014 * * \\
(0.007)\end{array}$ & $\begin{array}{l}-0.004 \\
(0.007)\end{array}$ & $\begin{array}{c}-0.007 \\
(0.007)\end{array}$ \\
\hline Born in US & $\begin{array}{c}1.174 * * * \\
(0.388)\end{array}$ & $\begin{array}{c}1.165^{* * * *} \\
(0.389)\end{array}$ & $\begin{array}{c}1.174 * * * \\
(0.376)\end{array}$ & $\begin{array}{c}1.178^{* * * *} \\
(0.379)\end{array}$ \\
\hline Married & $\begin{array}{c}0.573 * * * \\
(0.215)\end{array}$ & $\begin{array}{l}0.506^{* *} \\
(0.216)\end{array}$ & $\begin{array}{c}0.581 * * * \\
(0.209)\end{array}$ & $\begin{array}{c}0.529 * * \\
(0.210)\end{array}$ \\
\hline Years of Education & $\begin{array}{c}0.000 \\
(0.045)\end{array}$ & $\begin{array}{c}0.003 \\
(0.046)\end{array}$ & $\begin{array}{l}-0.008 \\
(0.044)\end{array}$ & $\begin{array}{l}-0.007 \\
(0.045)\end{array}$ \\
\hline Employed & $\begin{array}{c}-0.638^{* * * *} \\
(0.220)\end{array}$ & $\begin{array}{c}-0.709^{* * * *} \\
(0.220)\end{array}$ & $\begin{array}{c}-0.569 * * * \\
(0.213)\end{array}$ & $\begin{array}{c}-0.643 \text { *** } \\
(0.214)\end{array}$ \\
\hline \multicolumn{5}{|l|}{ Household Income } \\
\hline 2nd Quartile & $\begin{array}{c}0.028 \\
(0.282)\end{array}$ & $\begin{array}{c}0.058 \\
(0.282)\end{array}$ & $\begin{array}{c}0.049 \\
(0.274)\end{array}$ & $\begin{array}{c}0.070 \\
(0.274)\end{array}$ \\
\hline 3rd Quartile & $\begin{array}{l}-0.328 \\
(0.311)\end{array}$ & $\begin{array}{l}-0.291 \\
(0.310)\end{array}$ & $\begin{array}{l}-0.269 \\
(0.301)\end{array}$ & $\begin{array}{l}-0.249 \\
(0.302)\end{array}$ \\
\hline 4th Quartile & $\begin{array}{c}-0.594 * \\
(0.321)\end{array}$ & $\begin{array}{l}-0.566^{*} \\
(0.321)\end{array}$ & $\begin{array}{l}-0.547^{*} \\
(0.311)\end{array}$ & $\begin{array}{l}-0.543^{*} \\
(0.312)\end{array}$ \\
\hline $\begin{array}{l}\text { Racial Background } \\
\text { Black }\end{array}$ & $0.720 *$ & $0.685 *$ & $0754 * *$ & $0.689 *$ \\
\hline
\end{tabular}




\begin{tabular}{lcccc} 
& $(0.372)$ & $(0.378)$ & $(0.361)$ & $(0.367)$ \\
Asian & -0.416 & -0.608 & -0.468 & -0.639 \\
Native American & $(0.726)$ & $(0.724)$ & $(0.704)$ & $(0.704)$ \\
& -0.548 & -0.697 & -0.034 & -0.187 \\
Pacific Islander/Hawaiian & $(0.624)$ & $(0.625)$ & $(0.608)$ & $(0.610)$ \\
Hispanic & -1.749 & -1.692 & -0.799 & -0.780 \\
Mixed Race & $(1.966)$ & $(1.948)$ & $(1.910)$ & $(1.897)$ \\
Observations & -0.391 & -0.440 & -0.389 & -0.443 \\
R-Squared & $(0.336)$ & $(0.337)$ & $(0.325)$ & $(0.327)$ \\
\hline
\end{tabular}

Notes. Models also control for the number of surveys that respondents were asked to complete.

Omitted category in Household Income are respondents in the first (i.e., lowest) quartile of household income. $* * * \mathrm{p}<0.01, * * \mathrm{p}<0.05, * \mathrm{p}<0.1$ 
Figure 1: Distribution of Individual Survey Completion Rates

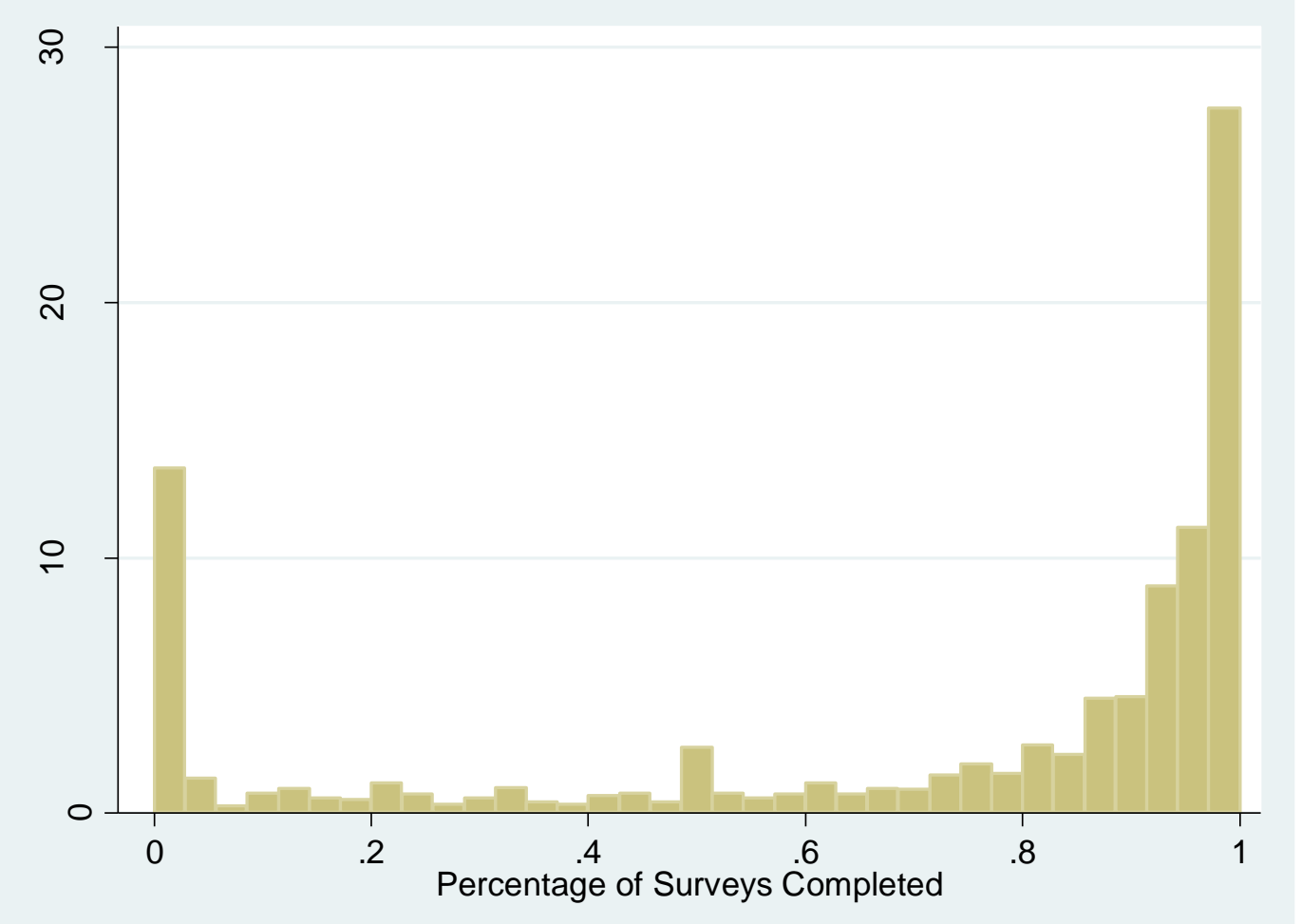

Note: Figure displays the percentage of respondents who completed a given percentage of the surveys that they were asked to complete. 